\title{
Does Distance Still Matter For Internal Migration And, If So, How? Evidence From 1986 To 2006
}

\author{
Omoniyi Alimi \\ NIDEA, University of Waikato \\ David C. Maré \\ Motu Research \& NIDEA, University of Waikato \\ Jacques Poot \\ NIDEA, University of Waikato
}

\begin{abstract}
In this paper we re-examine the structure of internal migration flows in New Zealand. We use data on gross migration flows between the 39 main and secondary urban areas for the four intercensal periods between 1986 and 2006. We confirm that the gravity model - in which migration is inversely related to distance - fits the data well, and that the way in which distance is measured (travel time, road distance or straight-line distance) matters to some extent for the goodness of fit of the model. We also show that some forms of socioeconomic differences influence migration in the same way as distance. Perhaps surprisingly, we find that the deterrence effect of distance on migration was increasing, at least until 2001. Improvements in connectivity through reduced travel time have not increased migration flows.
\end{abstract}

\section{Introduction}

Internal migration is an important component of sub-national population dynamics in New Zealand. A recent international comparison shows that New Zealand has one of the highest rates of internal migration in the world (Esipova, Pugliese and Ray, 2013). Empirical evidence from a wide range of countries during the last half century has shown that the process of internal migration has many structural determinants and that migrants are self-selected in terms of certain personal and locational characteristics. ${ }^{1}$ Given the growing divergence in regional population trends in New Zealand, with persistent population growth in Auckland coinciding with rapid population ageing and depopulation of many provincial and rural areas (e.g., Jackson, 2011), it is important to revisit the determinants of internal migration in the New Zealand context.

Hence we provide in this paper new evidence on key area and personal characteristics that determine internal migration in New Zealand. We focus specifically on how distance matters for internal migration in New Zealand. We compare three different measures of distance in a gravity model framework and provide evidence on which of these three measures explains internal migration flows in New Zealand best. We find that the deterrence effect of distance on migration has been increasing, at least until 2001, but the way in which distance is measured (road distance or travel time) does not appear to matter much, although a model with travel time fits migration flows slightly better than models with distance. Improvements in connectivity through reduced travel time between origin-destination pairs have not increased migration flows.

We also show that socioeconomic differences between the origin urban area and the destination urban area - in terms of the distribution of the population across occupations and across 
ethnicities - are a form of socioeconomic distance that influences migration in the same inverse way (greater distance means less migration) as geographical distance. On the other hand, a greater dissimilarity between cities in terms of the age distribution and the distribution of workers across industries leads to greater, rather than smaller, migration flows.

\section{Related Research}

Worldwide, there is an abundance of literature concerning diverse aspects of migration. Cushing and Poot (2004) noted that about 12,000 journal articles had been written on migration in economics journals since 1969 - and it is expected that this number will have increased considerably over the decade since their survey was published. Excellent literature surveys already exist in the migration field: Greenwood (1997) and Lucas (1997) provide good reviews of the literature on internal migration in developed and developing countries respectively; Borjas (2014) presents a comprehensive survey of the literature on international migration; and Cushing and Poot (2004) thoroughly detail advances in migration modelling.

Greenwood (1997) reviews the distance deterrence effect on internal migration. He finds that the distance elasticity of migration, the percentage decline in migration from $i$ to $j$ that results from a $1 \%$ increase in the distance between $i$ and $j$, other factors held constant) to vary widely between -0.1 and -0.2 , depending on many study and regression characteristics. Niedomysl et al. (forthcoming) review the effectiveness of different geographical measures of distance and conclude that distances inferred from regional population centroids are more accurate than distances inferred from area centroids. Interestingly, the issue whether travel time is a better proxy for migration costs than travel distance is not addressed in reviews such as Greenwood (1997) and Niedomysl et al. (forthcoming). This issue will be investigated in the present paper.

In the New Zealand context, Poot (1986) contains references to the literature until the 1980s. This paper developed and estimated an econometric model of 1976-1981 inter-urban labour migration of males within New Zealand. It was found that economic factors were the most important determinant of their inter-urban migration. The migration flows between urban areas were inversely related to the generalised cost of migration. Travel time between urban areas was a key factor determining the cost of migration. Migrants generally moved away from the colder south of New Zealand and from places with relatively low median incomes to places with high median incomes.

Maré and Timmins (2001) examined the link between local labour market adjustment and internal migration in New Zealand, based on data corresponding with the 1986-1991 and 19911996 intercensal periods. They estimated exploratory econometric models of migration that reconfirmed the gravity model of migration, which also underpinned the modelling by Poot (1986). Migration flows are positively correlated with the populations of the origin and destination regions and inversely related with the distance between the two regions. Additionally it was found that more densely populated regions had net inflows. Various migrant characteristics such as age and ethnicity mattered too. Using micro data from the 2001 and 2006 censuses, Sin and Stillman (2015) find that Māori are on average more geographically mobile than non-Māori. Māori who live outside the region that is home to their iwi are more responsive to local labour market shocks than Europeans, in contrast with Māori who live within their local iwi area. The latter are mostly unresponsive to such shocks.

A disadvantage of census-data based modelling of internal migration is that behaviour is inferred from the estimated regression models but no direct information is available regarding the actual 
motives of migrants. To overcome this deficiency in the New Zealand literature, Statistics New Zealand conducted a Survey of Dynamics and Motivation for Migration (DMM) in the first quarter of 2007 as a supplement to the Household Labour Force Survey. Following this DMM survey, a comprehensive (but purely descriptive) report on internal migration in New Zealand was published online (Statistics New Zealand, 2008). Subsequently, Morrison and Clark (2011) used the DMM survey data to show that only a minority of working-age migrants move between local labour markets primarily for employment reasons. Hence Morrison and Clark show a disconnect between observed net migration, which is usually positively correlated with employment growth, and stated migration motives, which include many other push and pull factors. Finally, Sloan (2013) used the DMM survey data to study the post-move satisfaction of individuals. He finds that post-move satisfaction is related to the characteristics of the migrants and of the move itself (the locations involved and the distance of the move).

\section{Data and Model Specification}

\section{The gravity model of migration}

The gravity model provides the basic modelling framework for this study (see Anderson, 2011, for a review). The gravity model of migration states that the number of people migrating between a particular origin and a particular destination is directly proportional to the product of the population of both origin and destination and inversely proportional to the distance between them. ${ }^{2}$ This model has performed well in explaining aggregate flows and has made important contributions to the migration literature since Ravenstein's (1889) early exposition. In a somewhat more general formulation, the impact of the origin and destination populations and of the distance between them is estimated by a regression model. The gravity regression model typically takes the form:

$$
\ln M_{i j}=a_{0}+a_{1} \ln P_{i}+a_{2} \ln P_{j}+a_{3} \ln D_{i j}+\epsilon \quad \text { (Equation 1) }
$$

where $M_{i j}$ is the migration flow between origin $i$ and destination $j, P_{i}$ is the population at the origin, $P_{j}$ is the population at the destination, and $D_{i j}$ is distance between origin $i$ and destination $j$. The natural logarithm is taken of all variables. The parameters $a_{0}, a_{1}, a_{2}$ and $a_{3}$ are to be estimated by e.g. Ordinary Least Squares (OLS) regression in which $\epsilon$ is a random error term.

\section{Description of Variables}

The basic gravity model is parsimonious, requiring only data on population, gross migration flows, and distance. We analyse migration flows between urban areas in New Zealand for all four 5-year intercensal periods between 1986 and 2006, and restrict our population and migration measures to people aged 25-54 at the time of the census to exclude those who are likely to migrate as dependents, students or retired persons. ${ }^{3}$ The data were derived from confidentialised unit records in the census files, accessed in the Statistics New Zealand data laboratory. Access to the data used in this study was provided by Statistics New Zealand under conditions designed to give effect to the security and confidentiality provisions of the Statistics Act 1975. The results presented in this study are the work of the authors, not Statistics New Zealand.

We focus on urban areas because New Zealand is a highly urbanised country (86 per cent of the resident population lived in urban areas in 2006). We use the Statistics New Zealand 2006 classifications to define the urban areas used in this study and consider only main and secondary urban areas since most of the urban area residents live in either of the two. Main urban areas have 
a population of at least 30,000 people, secondary urban areas have a population of between 10,000 and 30,000 people.

\section{Migration}

The dependent variable of the regression model $\left(\ln M_{i j}\right)$ is the natural logarithm of the gross migration flow between origin $i$ and destination $j$ for each of the 39 main and secondary urban areas of New Zealand in each of the four intercensal periods between 1986 and 2006. For this study, a migrant in a census is defined as someone in the 25 to 54 age bracket who is living in an urban area that is different from that which they were living at the time of the previous census. The number of migrants in each origin-destination pair is randomly rounded to base three, in accordance with Statistics New Zealand's confidentiality rules. For about 8 percent of origindestination pairs, the observed migration flow is zero, though for some of these the actual flow may be 1 or 2 . We set $\ln M_{i j}$ to be zero where the observed flow is zero, effectively assuming that the minimum number of migrants between any origin-destination pair is one. None of the main patterns discussed in this paper are sensitive to this assumption, although somewhat different point estimates are obtained if zero-flow observations are instead dropped from the regression.

It should be noted that the regression model in Equation (1) assumes, firstly, that the migration between any pair of urban areas $(i, j)$ is not related to the characteristics of any of the other urban areas; and, secondly, that inter-urban migration is not related to urban-rural or international migration. Methods that remove these assumptions are complex and therefore not pursued here. ${ }^{4}$ However, this is unlikely to impact on the results that we obtain with respect to the role of distance in migration modelling.

Table 1 shows basic descriptive statistics for each of the four intercensal periods. The number of origin-destination migration flows each year is $1,482(39 \times 38)$, with an average flow of slightly over 100 people. The largest flows in each year, of 8,000 to 10,000 people are flows between the four urban zones within the Auckland metropolitan area.

\section{Population variables}

The two population variables are the relevant population of origin areas $\left(P_{i}\right)$ and population of destination urban areas $\left(P_{j}\right)$, i.e. the total number of people aged 25 to 54 years in each of the 39 urban areas. All urban areas serve as both origin and destination. Population is measured at the end of the 5-year period over which migration is measured. Table 1 summarises population variation across the 39 urban areas. These vary in size from around 4,000 to well over 100,000.

\section{Distance variable}

The distance variable $\left(D_{i j}\right)$ is a measure of distance between origin and destination areas. Three different measures of distance are used in this study. They are: travel time in minutes; distance by road in kilometres; and straight-line distance between urban areas.

Travel time in minutes between origin urban area $i$ and destination urban area $j\left(D_{i j}^{M i n}\right)$ is the amount of time in minutes it would take to travel from the city centre of the origin urban area to the city centre of the destination urban area. Both current and 1984 estimates of travel time are used in this study. Current estimates are calculated using Google Maps and 1984 estimates are obtained from the 1984 Mobil Map. The 1984 measures were available for only 25 urban areas, giving $600(=25 * 24)$ origin-destination pairs.

Distance by road, in kilometres, between the city centre of origin urban area $i$ and destination urban area $j\left(D_{i j}^{K m}\right)$ has also been obtained by means of Google Maps and the 1984 Mobil Map. 
Straight-line distance between origin urban area $i$ and destination urban area $j\left(D_{i j}^{S K m}\right)$ is calculated as the distance between population-weighted centroids of the origin and destination areas. $^{5}$

Table 1 Summary statistics by intercensal period

\begin{tabular}{|c|c|c|c|c|c|c|}
\hline $\begin{array}{l}\text { Census } \\
\text { Period }\end{array}$ & Variable & Obs & Mean & Std. Dev. & Min & Max \\
\hline \multirow[t]{2}{*}{ 1986-1991 } & Population $\left(P_{i}\right.$ and $\left.P_{j}\right)$ & 39 & 26966 & 32177 & 4143 & 129480 \\
\hline & Migration flow $\left(M_{i j}\right)$ & 1482 & 100 & 390 & 0 & 7989 \\
\hline \multirow[t]{2}{*}{ 1991-1996 } & Population & 39 & 30238 & 37566 & 4200 & 155637 \\
\hline & Migration flow & 1482 & 105 & 424 & 0 & 8547 \\
\hline \multirow[t]{2}{*}{$1996-2001$} & Population & 39 & 31766 & 40640 & 4002 & 168852 \\
\hline & Migration flow & 1482 & 113 & 462 & 0 & 9666 \\
\hline \multirow[t]{11}{*}{$2001-2006$} & Population & 39 & 33663 & 44503 & 3699 & 184119 \\
\hline & Migration flow & 1482 & 112 & 484.8 & 0 & 10404 \\
\hline & & & \multicolumn{4}{|c|}{ Time invariant distance measures } \\
\hline & Straight-line distance in kilometres & 1482 & 418 & 293.3 & 12 & 1288 \\
\hline & & & \multicolumn{4}{|c|}{ Time variant distance measures } \\
\hline & 2013 Travel time in minutes & 1482 & 475 & 349 & 14 & 1440 \\
\hline & & $(600)$ & (553) & (358) & (41) & $(1440)$ \\
\hline & 2013 Road Map travel distance in kilometres & 1482 & 565 & 397 & 10 & 1784 \\
\hline & & $(600)$ & $(651)$ & $(409)$ & $(48)$ & $(1784)$ \\
\hline & 1984 Travel time in minutes & 600 & 783 & 486 & 55 & 2089 \\
\hline & 1984 Road Map travel distance in kilometres & 600 & 664 & 416 & 50 & 1852 \\
\hline
\end{tabular}

Observations for population are those for 39 urban areas. For migration flows and distance measures, there are $1,482(=39 * 38)$ observations, i.e. the origin-destination pairs formed from these 39 areas. 1984 travel times could only be obtained for origin-destination pairs of 25 urban areas $(25 * 24=600)$. Hence the 2013 distance measures have been calculated for both sets of urban areas. Population data is the usually resident population aged 25-54 for each urban area, migration flow is the number of migrants aged 25-54 whose urban area of usual residence was different in a census from what is was five years previously. Straight-line distance (in $\mathrm{km}$ ) between urban areas is calculated as the distance between populationweighted centroids. Current travel time in minutes and current road travel distance in kilometres are distance measures between origin and destination obtained from Google Maps in 2013. The 1984 distance measures are the travel time in minutes and road travel distance in kilometres between origin and destination obtained from the 1984 Mobil Road Map of New Zealand. Current travel time and distance in brackets are the corresponding current travel time and distance for the journeys for which travel time and distance were available in 1984. 
Table 1 contains summary measures of these distance variables. The 1984 time and distance measures are shown for the 600 pairs of urban areas for which data are available. The 2013 measures are shown for all 1,482 pairs, as well as for the subset of 600 pairs for which the 1984 data are available. Interurban distances vary widely, due to New Zealand's geography - for example in terms of travel time: from 14 minutes to 1,440 minutes (i.e., 24 hours - the time it takes to drive from Whangarei to Invercargill).

\section{Results}

The effect of different measures of distance and estimates of the distance elasticity of migration

Given three different measures of distance in a basic gravity model framework and four intercensal periods, we can estimate Equation 1 by means of 12 different regressions. The results are presented in Table 2. All the variables are significant at the one per cent level of significance for all time periods. The results from the regressions show that the specifications with travel time in minutes explains the highest proportion of the variation in migration flows in each period $(R-$ squared), followed by the specification with road distance in kilometres; while the model with the straight-line distance explains the least variation of all three models in all periods. This result is plausible: given that travel time reflects the opportunity cost of using that time for productive or leisure activities, economic theory would suggest that it is a better measure of the cost of migration than road distance (which proxies only the cost in use of a vehicle) to explain the crosssectional distribution of migration flows. Similarly, straight-line distance is the worst proxy of the distance deterrence effect on migration.

Interestingly, with respect to the distance elasticity of migration, the opposite order is found: straight-line distance has the greatest elasticity, followed by road distance and then travel time. However, the differences between these coefficients are not statistically significant. In any case, all elasticities are larger in magnitude in the travel distance regressions than in the travel time regression; and then larger again in the straight-line distance regressions. This simply reflects an omitted variable bias that biases the coefficients upwards in absolute value. For example, if migration within an agglomeration (such as the Auckland Council region) is greater than between agglomerations, the omission of an agglomeration variable would generate such an omitted variable bias. ${ }^{6}$ Moreover, the omitted agglomeration variable has a greater correlation with straight-line distance than with travel distance or travel time. Additionally, the results may be due to the way in which crossing Cook Strait has been represented. The Cook Strait crossing enters the road travel distance data as an $80 \mathrm{~km}$ journey while in terms of travel time this journey takes around three hours. The relatively longer measure of the Cook Strait crossing using travel time may also be responsible for the corresponding smaller coefficients in the gravity models.

The estimates of the distance elasticity of migration, regardless of the measure of distance, show an increase in the absolute value of the distance elasticity of migration between 1986-1991 and 1996-2001 (from 0.803 to 0.847 in the case of travel time). The absolute value of this elasticity of migration fell back to 0.806 in the 2001 to 2006 period. The increase in the distance elasticity of migration up to 2001 is against the expected result based on the information search hypothesis and the psychic cost hypothesis which argue that improvements in information and transportation technology over time will combine to reduce the deterring effect of distance. In his literature review, Greenwood (1997) concludes that the deterring effects of distance are likely to decline over time. 
Table 2 The distance impact on migration with different measures of distance

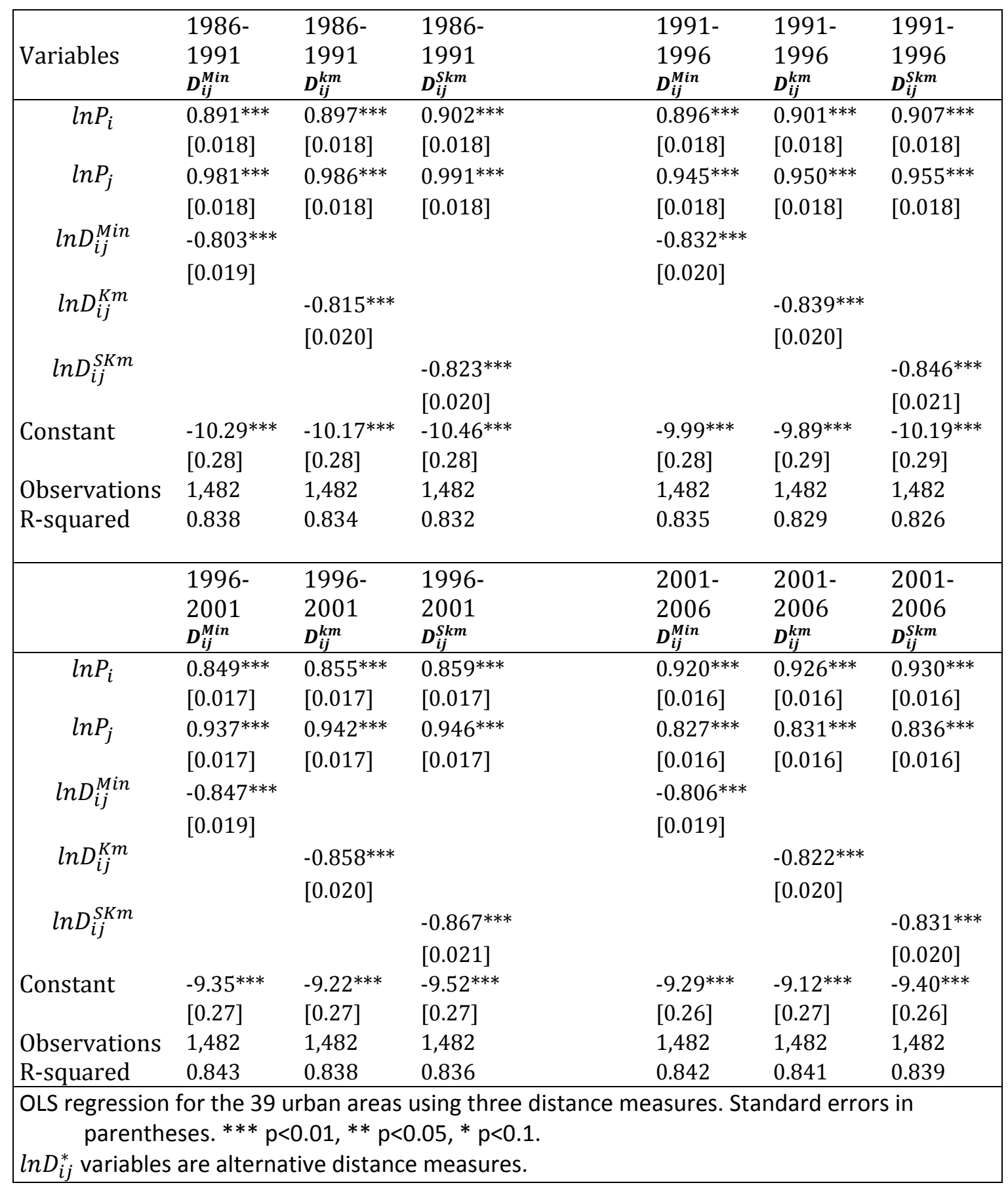

The counterintuitive New Zealand result probably reflects a combination of an increase in short distance moves (defined as moves between areas less than $200 \mathrm{~km}$ apart) compared to long distance moves (defined as moves between areas greater than $200 \mathrm{~km}$ apart) - which would increase the observed distance deterrence effect - combined with strong economic growth outside Auckland during the 2001-06 period, which would decrease the distance deterrence effect. Examining the migration and distance data shows that in the 1986 to 1991 period, the number of short distance moves was only about 1.1 times that of long distance moves but by the 2001 to 2006 period, the ratio had increased to 1.3. Most New Zealanders are increasingly moving shorter distances over time and this could explain the increasing distance elasticity of migration. 
In all periods, except for 2001 to 2006, the coefficient on destination population is greater than the coefficient on origin population. This implies that the population of the destination has a bigger impact on migration flows and migrants are attracted to larger destination areas. This trend is a reflection of migration inflows into the bigger centres, especially Auckland. The "role reversal" of $P_{i}$ and $P_{j}$ between the 1996-2001 and 2001-2006 periods is again due to population growth due to internal migration being much faster outside Auckland in the latter period than in the former. In fact, the reduced internal migration to Auckland areas reduced the estimated attractor effect of the population size in the destination. Net migration into the four urban areas of Auckland reduced from a gain of 6402 people in the 1986 to 1991 period to a net loss of 2823 people in the 2001 to 2006 period. An important point to note is that this analysis also excludes international migration which constitutes a significant proportion of the migrant inflows and outflows in Auckland.

\section{Does the gravity function fit the data?}

The simple 'linear in logs' functional form of Equation 1 is highly restrictive. To test whether the effects of distance are non-linear, we present a partial regression plot of the variation that identifies the coefficient on distanc.e For this purpose, we measure distance as travel time. We first regress $\ln M_{i j}$ on $\ln P_{i}, \ln P_{j}$, and a full set of year intercepts and save the residual as a measure of 'residual migration variation' $\left(u_{M}\right)$. We then regress $\ln D_{i j}^{M i n}$ on the same set of covariates and save the residual as a measure of 'residual travel time variation' $\left(u_{D}\right)$. To aid presentation, we rank all origin-destination pairs by $u_{D}$ and divide them into deciles. Figure 1 plots mean values of $u_{M}$ against mean values of $u_{D}$ for each decile. It also plots a straight line, fitted to the decile points. The slope of this line equals the coefficient on a pooled gravity equation that includes year intercepts (Frisch and Waugh, 1933). It is easy to see from the figure that this slope is about $2.5 / 3.2=-0.78$, a little less than the estimates in Table 2 . However, the relationship between the natural logarithm of migration and the natural logarithm of distance is clearly very close to linear, as is evident in the closeness of the linear fitted line and the 'semi-parametric' line connecting the decile means.

\section{Do other types of distance and difference between urban areas matter?}

Migration flows are reduced by geographic distance between origin and destination urban areas. Other forms of distance may also affect migration flows. In this section we consider the impact of socioeconomic distance on migration flows, using dissimilarities between origin and destination urban areas in composition. We use a dissimilarity index: $D D=\frac{1}{2} \sum_{i}\left|\lambda_{i}^{O}-\lambda_{i}^{D}\right|$, where $\lambda_{i}^{a}$ is the proportion of people in area $a$ (origin or destination) who belong to group $i$. (Duncan and Duncan, 1955). The index captures the proportion of people who would have to change categories to make the composition of the origin and destination regions the same. We define groups for industry (17 ANZSIC96 Divisions), occupation (9 NZSCO Major Groups), ethnicity (6 ethnic groups - grouped total responses), age (14 5-year age groups, with ages 65-99 grouped as one), and labour force status (4 categories - FT, PT, U, NILF).

Panel (a) of Table 3 summarises the variation in the measures of socioeconomic distances. On average, between 6 and 17 percent of people would have to change group to give origindestination pairs the same composition, depending on the measure. Industry and ethnicity differences are the most pronounced, with a mean value of 16-17 percent, but with pairwise differences ranging from 1 percent to 45 percent. Age and occupation differences between urban areas are the least pronounced. 


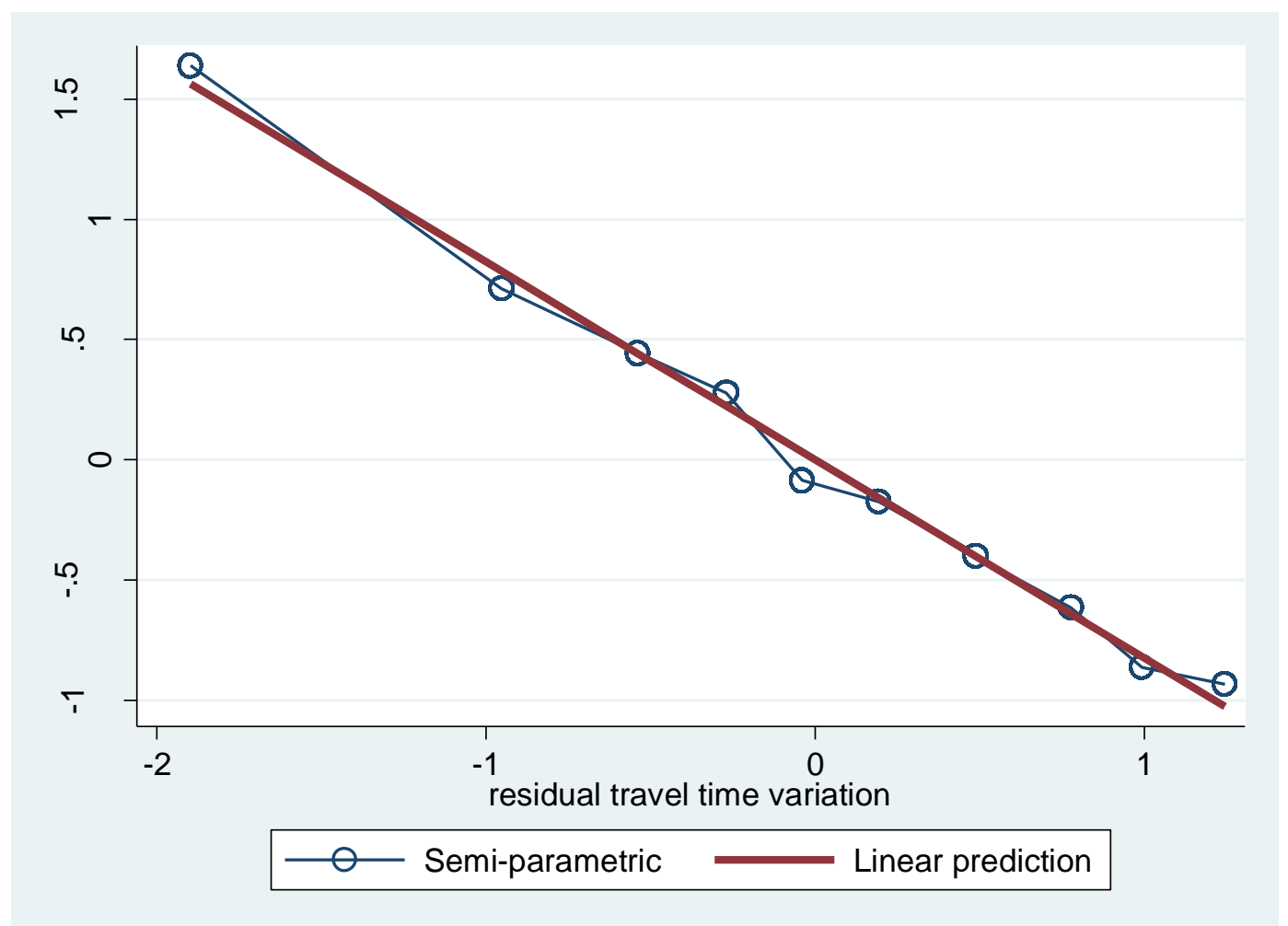

Panel (b) of Table 3 reports estimates from a gravity regression for the 2001-2006 period that includes lagged measures of socioeconomic distance as well as travel time as a measure of geographic distance. The coefficient on travel time $(-0.763)$ is slightly smaller than shown in Table 2 (-0.806), suggesting that some of deterrent effect of travel time estimated in Table 2 is the result of the fact that distant urban areas also tend to have less similar socioeconomic characteristics (another omitted variable bias in Table 2). The travel time effect is still, however, significant. Inter-urban differences in occupation and ethnicity are associated with lower migration flows, playing a similar role to geographic differences. In contrast, age and industry differences are associated with higher flows, possibly reflecting life cycle migration flows and regional labour market adjustment. Differences in labour force status do not significantly affect migration.

Although the coefficients of socio-economic differences are larger than the coefficient on travel time, the effects are weaker. A one standard deviation in the natural log of travel time reduces migration flows on average by about 0.5 standard deviations in the natural log of migration. A one standard deviation change in socioeconomic distances affects migration flows by between 0.05 (for industry differences) and 0.2 (for ethnicity differences) standard deviations in the natural log of migration. 
Table 3 The impact of socio-economic distance, 2001-2006

(a) Summary statistics for socioeconomic distance measures

\begin{tabular}{|c|c|c|c|c|}
\hline Variables & Mean & Std deviation & Min & Max \\
\hline Lag DD_occupation & $7.6 \%$ & $3.8 \%$ & $1.4 \%$ & $20.7 \%$ \\
\hline Lag $D D_{-}$ethnicity & $15.6 \%$ & $9.8 \%$ & $0.9 \%$ & $44.9 \%$ \\
\hline Lag $D D \_a g e$ & $5.9 \%$ & $3.4 \%$ & $0.4 \%$ & $20.9 \%$ \\
\hline Lag $D D_{-}$industry & $17.0 \%$ & $6.5 \%$ & $4.0 \%$ & $44.2 \%$ \\
\hline Lag DD_labour force status & $12.1 \%$ & $6.1 \%$ & $1.9 \%$ & $39.4 \%$ \\
\hline
\end{tabular}

(b) Regression estimates

\begin{tabular}{|lll|}
\hline Variables & Log of migration & Std. error \\
\hline $\ln P_{i}$ & $0.866^{* * *}$ & {$[0.016]$} \\
$\ln P_{j}$ & $0.959^{* * *}$ & {$[0.016]$} \\
$\boldsymbol{l n} \boldsymbol{D}_{\boldsymbol{i j}}^{\text {Min }}$ & $-0.763^{* * *}$ & {$[0.019]$} \\
Lag DD_occupation & $-3.371^{* * *}$ & {$[0.644]$} \\
Lag DD_ethnicity & $-2.142^{* * *}$ & {$[0.213]$} \\
Lag DD_age & $2.311^{* * *}$ & {$[0.683]$} \\
Lag DD_industry & $1.201^{* *}$ & {$[0.612]$} \\
Lag DD_labour force status & -0.968 & {$[0.656]$} \\
Constant & $-9.884^{* * *}$ & {$[0.280]$} \\
Observations & 1,482 & \\
R-squared & 0.859 & \\
\hline OLS regression for 39 urban areas. Variables labelled as $D_{-}^{*}{ }^{*}$ are dissimilarity indices. Standard \\
\multicolumn{2}{r}{ errors in parentheses. ${ }^{* * *} \mathrm{p}<0.01, * * p<0.05,{ }^{*} \mathrm{p}<0.1}$. \\
\hline
\end{tabular}

\section{Do improvements in connectivity promote migration flows?}

In the bottom panel of Table 1 we can compare travel times in 1984 and 2013 among the 600 origin destination pairs for which consistent data are available. There was on average a 30 per cent reduction in travel time across New Zealand, from 783 minutes to 553 minutes. Most of these changes can be attributed to improvements in roads linking the different urban areas in New Zealand and changes to the speed limit of travel by road (the speed limit of travel on the open road in New Zealand was $80 \mathrm{~km}$ per hour between 1973 and 1985). This section uses a panel fixed effects model to examine the effect of improved connectivity (reduction in travel time) on migration flows using data from the 1991 and 2006 censuses. A panel model was estimated on a dataset consisting of 600 observations for which travel times are available for both 1991 and 2006 census periods. As discussed earlier, historical travel time information was not available for all the 39 urban areas and this limited the analysis to the 25 urban areas in which comparable travel time information was available. The following fixed effect panel model was estimated:

$$
\operatorname{lnM}_{i j t}=a_{0}+a_{1} \ln P_{i t}+a_{2} \ln P_{j t}+a_{3} \operatorname{lnTVMIN} N_{i j t}+f_{i j}+\delta_{t}+\epsilon_{i j t} \quad \text { Equation (2) }
$$

where $M_{i j t}, P_{i t}$, and $P_{j t}$ represent migration flows, population of origin and population of destination in period $t$ (1986-1991 and 2001-2006) respectively, TVMIN represents the time varying measure of distance in minutes (the 1984 and 2013 measures of distance between urban areas) and $\boldsymbol{\delta}_{\boldsymbol{t}}$ represents a time dummy for the year 2006. Fixed effects for each origin-destination pair are included as $\boldsymbol{f}_{\boldsymbol{i} \boldsymbol{j}}$. The results from the panel model are reported in Table 4 .

The results show no evidence that improvements in connectivity brought about by upgraded road infrastructure and changes in speed limits have led to increased migration flows. The coefficient on the time varying measure of distance has a positive sign which is against expectation because 
it would suggest that a reduction in travel time between any given origin-destination pair would lead to a reduction in migration between the two urban areas. This result is, however, not significant at conventional statistical significance levels. The positive coefficient may be due to the fact that improved connectivity between urban areas has led to increased commuting instead of increased migration. There is certainly evidence of increasing fly-in/fly-out and drive-in/drive out in Australia (Perry and Rowe, 2015) and trans-Tasman (Kukutai and Pawar, 2013). The extent to which this is currently taking place in response to the construction activity in Christchurch after the earthquakes or the high house prices in Auckland is an interesting question for future research.

Table 4 Panel fixed effects model using a time-varying measure of distance (1986 and 2006)

\begin{tabular}{|ll|}
\hline VARIABLES & Log of migration flows \\
\hline & \\
Population of origin & 0.0199 \\
& $(0.16)$ \\
Population of destination & $1.464^{* * *}$ \\
& $(0.16)$ \\
Time varying measure of distance (minutes) & 0.249 \\
& $(0.18)$ \\
Time dummy (2006) & -0.0552 \\
& $(0.08)$ \\
Constant & $-12.75^{* * *}$ \\
& $(2.66)$ \\
& 1,200 \\
Observations & 600 \\
Number of origin-destination pairs & 0.12 \\
R-squared (within) & 0.24 \\
R-squared (between) & \\
\hline OLS fixed effect regression using time varying distance measure (travel time) for 25 urban areas. \\
Standard errors in parentheses. ${ }^{* * *} p<0.01,{ }^{* *} p<0.05,{ }^{*} p<0.1$. & \\
\hline
\end{tabular}

\section{Conclusion}

The evidence presented in this paper confirms that distance, as captured by travel time, road distance or straight-line distance, does still matter and is a significant factor in discouraging internal migration in New Zealand.

There have been changes in the strength of the deterrence effect of distance over our sample period. The distance elasticity of migration increased in all periods until the 1996 to 2001 period and then decreased slightly in the 2001 to 2006 period. These results are at odds with the hypothesis that suggests that improvements in information and communication technology would imply a decline in the distance elasticity of migration. The results are, however, consistent with the increase in the number of short distance moves relative to long distance ones.

Travel time differences account for slightly more of the variation in migration than do other distance measures but the differences are not great. The widely-used gravity model of migration flows fits the data well - explaining over 80 percent of the variation in flows between urban areas in New Zealand. Furthermore, the functional form of the gravity model, and in particular the linearity of the relationship between the log of distance and the log of migration flows is well supported by the data. 
We show that some forms of socioeconomic difference deter migration flows in the same way as physical distance. In particular, differences between urban areas in occupation and ethnic composition are associated with lower migration flows. In contrast, industry and age differences appear to strengthen flows between urban areas, possibly due to regional labour market adjustment and life-cycle migration respectively.

We use changes in inter-urban travel times between 1984 and 2013 to estimate the impact of improved connectivity between urban areas on migration flows. There is no evidence that reduced inter-urban travel times have increased migration flows.

\section{Future Research}

The gravity model of migration is a versatile foundation for a wide range of migration studies. It can be modified by the inclusion of a range of measures on the attractiveness of origin and destination areas and the composition of the population in these areas. The effects of these added covariates can shed light on the relative importance of socioeconomic and labour market characteristics on migration flows, and hence on the role of migration in reinforcing or dissipating differences across areas.

Alimi (2014) has investigated the determinants of migration in New Zealand within this framework. He finds evidence that income growth within an area attracts migrants and deters migration outflows as expected. The study also confirms the role of rainfall and sunshine as "amenity" factors that may influence migration. An increase in sunshine hours will increase migration inflows to a destination and reduce outflows from an origin. This is consistent with international evidence on net migration to "sunbelt regions' in recent decades. Evidence on rainfall reveals that droughts increase outflows from origin areas but there is contrasting evidence on the effect of rainfall on inflows to destination areas. He also finds evidence that internal migration may be working to accelerate demographic imbalances. Further investigation of the interaction of migration and differences in demographic structure within cities would be valuable.

An additional avenue for future research on internal migration is offered by Statistics New Zealand's Integrated Data Infrastructure (IDI). This provides longitudinal information on individuals' location, as well and on a range of labour market and other activities obtained from administrative and survey sources. Similarly, the linked census (Didham et al, 2014) has the potential to provide a longer-term / life-course perspective in the analysis of the determinants and consequences of internal migration flows.

\section{Notes}

1 For reviews of the international literature on internal migration, see, e.g.: Cushing and Poot (2004); Greenwood (1997) and Lucas (1997).

2 This is analogous to Newton's gravity model in physics, except that in the latter the "interaction" (force) is inversely proportional to the square of distance.

3 At the time this study was conducted, the corresponding 2013 census data were not yet available.

4 On the former issue, see Poot (1986); and on the latter: Poot (1995).

5 Manukau city centre was the reference point for South Auckland urban area, Henderson for West Auckland, North Shore Information centre for North Auckland and Auckland city centre for Central Auckland urban area. The distance and travel time chart of the 1984 Mobil Travel 
Map was the source of distance measures in 1984. For straight-line distance, geographic centroids were calculated for each meshblock, derived from 2006 meshblock shape files available on the Statistics New Zealand website. Population-weighted means of longitude and latitude were then calculated for each urban area to give the representative location of the urban area.

6 Peeters (2012) shows how such omitted variable bias can be avoided by means of a new estimator, the Generalised Maximum Entropy estimator, which accounts explicitly for spatial structure.

\section{References}

Alimi, 0. B. (2014). Determinants of Internal Migration in New Zealand: A Modified Gravity Approach. Masters of Management Studies dissertation. Hamilton, NZ: University of Waikato.

Anderson, J.E. (2011). The gravity model. Annual Review of Economics, 3: 133-160.

Borjas, G. J. (2014). Immigration Economics. Boston: Harvard University Press.

Cushing, B., and Poot, J. (2004). Crossing boundaries and borders: Regional science advances in migration modelling. Papers in Regional Science, 83(1), 317-338.

Didham, R. A., Dobson, W., and Nissen, K.. (2014). Linking Censuses: New Zealand Longitudinal Census 1981-2006. Wellington: Statistics New Zealand.

Duncan, O. D., and Duncan, B. (1955). Residential distribution and occupational stratification. The American Journal of Sociology, 60(5), 493-503.

Esipova, N., Pugliese, A., and Ray, J. (2013). The demographics of global internal migration. Migration Policy Practice Journal, 3(2), 3-5.

Frisch, R., and Waugh, F. V. (1933). Partial time regressions as compared with individual trends. Econometrica 1(4): 387-401.

Greenwood, M. J. (1997). Internal migration in developed countries. In M. R. Rosenzweig, and 0. Stark (Eds.), Handbook of Population and Family Economics. Volume 1B. Amsterdam: Elsevier.

Jackson, N. (2011). The Demographic Forces Shaping New Zealand's Future: What Population Ageing Really Means. NIDEA Working Paper No. 1. Hamilton NZ: University of Waikato.

Kukutai, T. and Pawar, S. (2013) A Socio-demographic Profile of Māori Living in Australia. NIDEA Working Paper No. 3. Hamilton NZ: University of Waikato.

Lucas, R. B. (1997). Internal migration in developing countries. In M. R. Rosenzweig, and O. Stark (Eds.), Handbook of Population and Family Economics. Volume 1B. Amsterdam: Elsevier.

Maré, D. and Timmins, J. (2001). Internal migration and regional adjustment: some preliminary issues. In: P.S. Morrison (Ed.) Labour, Employment and Work in New Zealand 2000. Proceedings of the Ninth Conference. Wellington NZ: Victoria University of Wellington. 
Morrison, P. S., and Clark, W. A. V. (2011). Internal migration and employment: macro flows and micro motives. Environment and Planning A, 43, 1948-1964.

Niedomysl, T., Ernstsson, U. and Fransson, U. (forthcoming). The accuracy of migration distance measures. Population, Space and Place.

Perry, M. and Rowe, J.E. (2015). Fly-in, fly-out, drive-in, drive-out: The Australian mining boom and its impact on the local economy. Local Economy 30(1), 139-148.

Peeters, L. (2012). Gravity and spatial structure: the case of interstate migration in Mexico. Journal of Regional Science 52(5), 819-856.

Poot, J. (1986). A system approach to modelling the inter-urban exchange of workers in New Zealand. Scottish Journal of Political Economy, 33, 249-274.

Poot, J. (1995). Do borders matter? A model of interregional migration in Australasia. Australasian Journal of Regional Studies, 1(2), 159-182.

Ravenstein, E. G. (1889). The laws of migration. Journal of the Royal Statistical Society, 52(2), 241-305.

Sin, I. and Stillman, S. (2015). Economic Liberalisation and the Mobility of Minority Groups: Evidence from Maori in New Zealand. Motu Working Paper 15-03. Wellington NZ; Motu Economic and Public Policy Research.

Sloan, M. (2013). The Post-move Satisfaction of Individuals Moving within New Zealand. PhD thesis. Wellington, New Zealand: Victoria University of Wellington.

Statistics New Zealand (2008). Internal Migration. Wellington, New Zealand: Statistics New Zealand. Retrieved from http://www.stats.govt.nz/browse for stats/population/Migration/internalmigration.aspx 